\title{
Preparation of a Sustained Release Drug Delivery System for Dexamethasone by a Thermosensitive, In Situ Forming Hydrogel for Use in Differentiation of Dental Pulp
}

\author{
Elham Khodaverdi, ${ }^{1}$ Fatemeh Kheirandish, ${ }^{2}$ Farnaz Sadat Mirzazadeh Tekie, ${ }^{3}$ \\ Bibi Zahra Khashyarmanesh, ${ }^{4}$ Farzin Hadizadeh, ${ }^{5}$ and Hamideh Moallemzadeh Haghighi ${ }^{4}$ \\ ${ }^{1}$ Targeted Drug Delivery Research Center, School of Pharmacy, Mashhad University of Medical Sciences, Mashhad, Iran \\ ${ }^{2}$ Student Research Committee, School of Pharmacy, Mashhad University of Medical Sciences, Mashhad, Iran \\ ${ }^{3}$ Medical Nanotechnology Research Centre, Tehran University of Medical Sciences, Tehran, Iran \\ ${ }^{4}$ Department of Medicinal Chemistry, School of Pharmacy, Tehran University of Medical Sciences, Mashhad, Iran \\ ${ }^{5}$ Biotechnology Research Center, School of Pharmacy, Mashhad University of Medical Sciences, Mashhad, Iran
}

Correspondence should be addressed to Farzin Hadizadeh; hadizadehf@mums.ac.ir

Received 1 October 2013; Accepted 28 October 2013

Academic Editors: S. Calis and R. Zelkó

Copyright (C) 2013 Elham Khodaverdi et al. This is an open access article distributed under the Creative Commons Attribution License, which permits unrestricted use, distribution, and reproduction in any medium, provided the original work is properly cited.

\begin{abstract}
In situ forming delivery systems composed of block copolymers are attracting substantial attention due to their ease of use, biocompatibility, and biodegradability. In this study, the thermoresponsive triblock copolymer PLGA-PEG-PLGA was studied as a dexamethasone delivery system. Dexamethasone, a synthetic glucocorticoid, is used clinically to improve inflammation, pain, and the hyperemesis of chemotherapy, and it is applied experimentally as a differentiation factor in tissue engineering. PLGAPEG-PLGA was synthesised under microwave irradiation for $5 \mathrm{~min}$. The obtained copolymer was characterised to determine its structure and phase transition temperature. An in vitro release study was conducted for various copolymer structures and drug concentrations. The yield of the reaction and HNMR analysis confirmed the appropriateness of the microwave-assisted method for PLGA-PEG-PLGA synthesis. Phase transition temperature was affected by the drug molecule as well as by the copolymer concentration and structure. An in vitro release study demonstrated that release occurs mainly by diffusion and does not depend on the copolymer structure or dexamethasone concentration.
\end{abstract}

\section{Introduction}

Pharmaceutical science has shown notable advancements in the development of novel drug delivery systems [1] in the form of microparticles $[2,3]$, nanoparticles $[4,5]$, and hydrogels $[6,7]$. Most of these new carriers are made of polymers and particularly the biodegradable di- and tri block copolymers composed of hydrophobic and hydrophilic blocks, such as hydrophobic polycaprolactone $[8,9]$, polylactide $[10,11]$, poly propylene oxide [12], polylactide glycolide [13], and hydrophilic polyethylene glycol [14] and polyethylene oxide [15]. The copolymer structure allows the ready formation of nanomicelles and hydrogels due to physical crosslinking between hydrophobic sections [16]. These copolymers could also show intelligent behaviour with respect to phase transition and drug release profile [17]. Current smart delivery systems are focused on thermo-responsive and in situ gelforming copolymers because of their ability to assume a gel form abruptly in response to a rise in temperature above the gelation temperature (the temperature at which the copolymer sol turns into a gel). This property makes a copolymer formulation injectable (sol) below body temperature and creates a sustained release system (gel) at body temperature [18-20].

PLGA-PEG-PLGA is a tri-block copolymer that consists of polyethylene glycol (PEG) and two polylactide glycolide (PLGA) blocks; the latter are composed of lactide (LA) and glycolide (GA) monomers. PLGA is a hydrophobic block due 
to the presence of LA, while PEG is a hydrophilic block. Zentner and coworkers were the first to synthesize this copolymer (Regel) and to demonstrate its thermoresponsiveness and in situ forming properties [21]. The copolymer is biocompatible and biodegradable; therefore, it is a good candidate as a drug delivery system [22].

Different therapeutic cargos such as DNA molecules, peptides (growth hormone [23], venom peptide [24]), proteins (insulin [25]), and other drug molecules (paclitaxol [21], naltrexone hydrochloride [26]) have been loaded into this hydrogel and both in vitro and in vivo investigation have demonstrated the suitability of PLGA-PEG-PLGA hydrogel for therapeutic applications. Various parameters such as PEG molecular weight (Mw), LA to GA ratio (LA : GA), tri-block copolymer Mw, copolymer concentration, and persistence of other molecules in the copolymer formulation (such as drugs and salts) can be manipulated to alter the properties of the system, such as its phase transition temperature, viscosity, swelling, degradation rate, and drug release profile [22, 2729].

Dexamethasone sodium phosphate (dex), the candidate drug for loading into the PLGA-PEG-PLGA hydrogel in this study, is a synthetic glucocorticoid (GC) that binds to the GC receptors presenting in most mammalian cells. The significant effect of GCs on suppressing immune system responses leads to their extensive use in treating diseases caused by overactivity of the immune system $[30,31]$. These drugs have often been prescribed to cancer patients to reduce side effects of chemotherapy such as hyperemesis and toxicity to normal tissue $[32,33]$. In addition, GCs exert proapoptotic effects on lymphoid cells [34]. However, Herr and coworkers confirmed that dex treatment induces the resistance of lung and cervical cancer cells to cisplatin, which has raised concerns about the coadministration of chemotherapeutic drugs and dex [35].

One study carried out on bone marrow stem cells indicated that chronic exposure of cells to dex induces their differentiation into osteogenic cells [36]. Ogata et al. showed that expression of the BSP gene in response to dex accounts for the differentiation of stem cells into osteoblasts [37]. Martins and coworkers prepared electrospun scaffolds loaded with dexamethasone as a differentiation factor for oestrogenic induction of bone marrow mesenchymal stem cells [38].

Another interesting use of dex is in dentistry, where this drug is considered as a potential treatment that promotes fibronectin synthesis and suppresses nerve growth factor secretion in tooth pulp [39]. A previous study indicated that dex stimulates differentiation of odontoblast-like cells in human dental pulp cultures, while reducing the proportion of smooth muscle actin-positive cells [40].

In the present study, we assumed that PLGA-PEG-PLGA hydrogel loaded with dex would be an appropriate system for use as a scaffold for tissue engineering and osteogenic induction of mesenchymal stem cells; moreover, it could be used for tooth pulp healing as a sustained release drug delivery system. We studied the effects of drug concentration and copolymer structure (LA:GA) on hydrogel properties. In addition, we investigated the in vitro release of dex from the hydrogel, and the release mechanism and effective parameters of its release profile were explored.

\section{Materials and Methods}

2.1. Materials. Glycolide A (GA), D,L-lactide (LA), and stannous 2-ethylhexanoate were acquired from Sigma-Aldrich, USA. Polyethylene glycol $(\mathrm{Mw}=1000)$, acetonitrile (HPLC grade), monobasic sodium phosphate, monobasic potassium phosphate, and sodium hydroxide were purchased from Merck Co., Germany. Dexamethasone sodium phosphate (dex) was provided by Osve Co., Iran.

2.2. Synthesis and Purification of PLGA-PEG-PLGA. PLGAPEG-PLGA was synthesised according to the previously reported method, with minor modifications [26], using a microwave assisted method and a Milestone MicroSYNTH. For this purpose, PEG (MW = 1000) was dried at $120^{\circ} \mathrm{C}$ under microwave irradiation and vacuum for $10 \mathrm{~min}$. Mixtures of LA : GA with ratios of $3: 1$ or $5: 1$ were combined with stannous 2-ethylhexanoate and added to the PEG reaction. The reaction mixture was again incubated under microwave irradiation at $150^{\circ} \mathrm{C}$ and $800 \mathrm{w}$ for $5 \mathrm{~min}$.

The resulting copolymer was purified by dissolving the product in $4^{\circ} \mathrm{C}$ water and precipitating at $80^{\circ} \mathrm{C}$. The supernatant contained impurities that do not precipitate at higher temperature and was discarded. The purified PLGA-PEGPLGA copolymer was then lyophilised.

2.3. Hydrogel Preparation. Copolymers were dispersed at concentrations of 17,23 , and $28 \% \mathrm{w} / \mathrm{v}$ into warm phosphate buffer (PBS, $\mathrm{pH}=7.4$ ), and incubated at $4^{\circ} \mathrm{C}$ overnight with continuous stirring by a magnetic stirrer to dissolve.

Drug loaded hydrogels were prepared by dissolving dex at a concentration of 0.1 and $0.4 \% \mathrm{w} / \mathrm{v}$ in the copolymer solution and transferring the mixture to a water bath $\left(37 \pm 0.1^{\circ} \mathrm{C}\right)$ until a gel formed.

\subsection{Triblock Copolymer and Hydrogel Characterisations}

2.4.1. ${ }^{1} \mathrm{H} N M R$. ${ }^{1} \mathrm{H}$ Nuclear magnetic resonance $\left({ }^{1} \mathrm{H}\right.$ NMR) spectroscopy was used to confirm the structure of the copolymers, to estimate the LA : GA ratio, and to calculate the number average molecular weight $(\mathrm{Mn})$ of the PLGA-PEGPLGA. ${ }^{1} \mathrm{H}$ NMR was carried out in $\mathrm{CDCl} 3$ using a Bruker AC-80 NMR instrument at $300 \mathrm{MHz}$ and $25^{\circ} \mathrm{C}$.

2.4.2. Evaluating the Phase Transition of the Hydrogel. The sol-gel transition temperature was investigated by the inverted test tube method [29]. Briefly, $1 \mathrm{~mL}$ of each solution was transferred to as refrigerated bath circulator (P-22, WISD, South Korea), and the temperature was increased at $1^{\circ} \mathrm{C} / \mathrm{min}$ from $0^{\circ} \mathrm{C}$ up to the point where gel formation occurred and then at the same rate until it precipitated. To confirm gel formation, the vial was inverted every 2 min to evaluate the flow of the formulation. The syringeability of the copolymer sol was evaluated by passing the formulation through a 25 gauge syringe needle. 
<smiles>CC(C)OCC(=O)CC(C)C(=O)OCCOC(C)(C)CCOC(C)(C)C(=O)OC(C)(C)O</smiles>

(a)

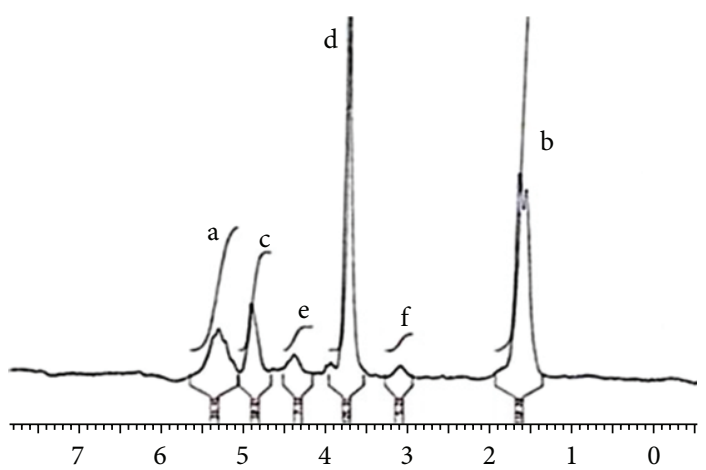

(b)

Figure 1: ${ }^{1} \mathrm{H}$ NMR spectrum of PLGA-PEG-PLGA (LA : GA = 3:1); signals a, c, e, d, $\mathrm{f}$, and b are associated with the $\mathrm{CH}_{\text {of }} \mathrm{LA}$, the $\mathrm{CH}_{2}$ of $\mathrm{GA}, \mathrm{CH}_{2}$ of PEG, another $\mathrm{CH}_{2}$ of PEG, and the $\mathrm{OH}$ and $\mathrm{CH}_{3}$ of LA, respectively.

2.5. In Vitro Study of Drug Loaded Hydrogels. After complete formation of the gel $(1 \mathrm{~mL})$ (after about $5 \mathrm{~min}$ incubation at $\left.37^{\circ} \mathrm{C}\right), 4 \mathrm{~mL}$ of PBS ( $\mathrm{pH} 7.4$ ) was poured above each gel as a release medium. The samples were shaken at $20 \pm$ $2 \mathrm{rpm}$ and incubated at $37^{\circ} \mathrm{C}$ in a reciprocal water bath (N-BIOTEK NB-304, South Korea). Samples were taken at $0,8,12$, and every $24 \mathrm{~h}$ (until release of the drug was complete) by withdrawing $1 \mathrm{~mL}$ of release medium, which was replaced by fresh medium. The samples were analysed by high performance chromatography (HPLC) with isocratic solvent delivery using a Waters (USA) 600 pump system equipped with a C18 column $(3.9 \times 150 \mathrm{~mm}$ Novapak C18). The mobile phase consisted of $70: 30$ acetonitrile: $\mathrm{PBS}(10 \mathrm{mM}, \mathrm{pH}=$ 3 ) at a flow rate of $1 \mathrm{~mL} / \mathrm{min}$ at $25^{\circ} \mathrm{C}$. The dex eluted from the column was detected with a UV/VIS detector (Waters 2487 dual absorbance detector) at $242 \mathrm{~nm}$. The volume of each injection was $20 \mu \mathrm{L}$ and each sample was analysed three times. Data were analysed using AzurV.4.0 software.

2.6. Statistics. The results were presented as means \pm SDs $(n=$ 4). Paired $t$-tests and one-way ANOVA were used to analyse the results with a significance level of $P<0.05$.

\section{Results}

3.1. Copolymer Synthesis and Characterisations. Copolymers with LA : GA ratios of $3(\mathrm{C} 1)$ and $5(\mathrm{C} 2)$ were prepared by a ring opening method using microwave irradiation. The yield of this reaction was greater than $85 \%$.

The ${ }^{1} \mathrm{H}$ NMR spectrum of $\mathrm{Cl}$ is shown in Figure 1, which shows an acceptable conformity with a previously reported spectrum for PLGA-PEG-PLGA. The signals appeared at 5.2
TABLE 1: Copolymer composition determined by ${ }^{1} \mathrm{H}-\mathrm{NMR}$.

\begin{tabular}{lcc}
\hline & LA $: G A$ & Mn \\
Theoretical & Practical & \\
\hline $3: 1$ & $2.9: 1$ & 3233.18 \\
$5: 1$ & $4.86: 0$ & 4684 \\
\hline
\end{tabular}

(a), 4.8 (c), 4.3 (e), 3.5 (d), 3 (f), and 1.5 (b) ppm associated with the $\mathrm{CH}$ of $\mathrm{LA}$, the $\mathrm{CH}_{2}$ of $\mathrm{GA}$, a $\mathrm{CH}_{2}$ of PEG, another $\mathrm{CH}_{2}$ of $\mathrm{PEG}$, and the $\mathrm{OH}$ and $\mathrm{CH}_{3}$ of $\mathrm{LA}$, respectively.

The $\mathrm{Mn}$ and LA : GA ratio estimated from obtained spectrums of $\mathrm{C} 1$ and $\mathrm{C} 2$ are presented in Table 1. These indicate an adequate similarity with theoretical values, confirming the suitability of this synthesis procedure.

3.2. Hydrogel Characterisations. The sol shape of the formulations was easily injectable since it passed effortlessly through the fine needle of a syringe. The phase transition temperatures of $\mathrm{C} 1$ and $\mathrm{C} 2$ were evaluated via the inverted test tube method as the temperature was increased. The sol-gel transition temperatures prior and subsequent to the drug loading are indicated in Table 2. All the formulations assumed the gel condition in less than $20 \mathrm{~s}$ after transfer to a $37^{\circ} \mathrm{C}$ water bath. Decreasing the temperature below the gelling temperature led to a reversal from the gel to the sol condition.

3.3. In Vitro Release Study. The $\mathrm{C} 1$ and $\mathrm{C} 2$ polymers at a concentration of $23 \%(\mathrm{w} / \mathrm{v})$ were chosen to prepare dex 0.1 and $0.5 \%(\mathrm{w} / \mathrm{v})$ loaded hydrogels intended for an in vitro 
TABLE 2: Gel formation temperature of copolymers.

\begin{tabular}{|c|c|c|c|c|c|c|}
\hline \multirow{3}{*}{$\begin{array}{l}\text { Copolymer conc. } \\
(\% \mathrm{w} / \mathrm{v})\end{array}$} & \multicolumn{6}{|c|}{ Drug conc. $(\% w / v)$} \\
\hline & \multicolumn{2}{|c|}{0} & \multicolumn{2}{|c|}{0.1} & \multicolumn{2}{|c|}{0.5} \\
\hline & $\mathrm{C} 1$ & $\mathrm{C} 2$ & $\mathrm{C} 1$ & $\mathrm{C} 2$ & $\mathrm{C} 1$ & $\mathrm{C} 2$ \\
\hline 28 & 14.7 & 13.3 & 14.4 & 13 & 14 & 13 \\
\hline 23 & 17.4 & 16.2 & 17 & 16 & 16.8 & 15.5 \\
\hline 17 & 21.2 & 20 & 21 & 19.5 & 20 & 19 \\
\hline
\end{tabular}

C1: PLGA-PEG-PLGA with LA : GA=3:1, C2: with LA: GA $=5: 1$; the sol to gel transition temperature $\left({ }^{\circ} \mathrm{C}\right)$ is written in bold.

TABLE 3: Kinetics model of release profile.

\begin{tabular}{lccccc}
\hline \multirow{2}{*}{$\begin{array}{l}\text { Drug conc. } \\
(\% \mathrm{w} / \mathrm{v})\end{array}$} & LA : GA & \multicolumn{2}{c}{ Zero order } & \multicolumn{2}{c}{ Higuchi } \\
& & Slope & $R^{2}$ & Slope & $R^{2}$ \\
\hline 0.1 & $3: 1$ & 0.239 & 0.893 & 5.037 & 0.987 \\
0.5 & $3: 1$ & 0.235 & 0.830 & 5.068 & 0.961 \\
0.1 & $5: 1$ & 0.232 & 0.916 & 4.82 & 0.984 \\
0.5 & $5: 1$ & 0.253 & 0.892 & 5.274 & 0.965 \\
\hline
\end{tabular}

release experiment. Figure 2 illustrates the release profile of dex at various concentrations from the $\mathrm{C} 1$ and $\mathrm{C} 2$ hydrogels.

The drug release mechanism was investigated by fitting zero order and the Higuchi kinetics models onto the obtained data (Table 3) [41]. Considering the calculated $R$ square $\left(R^{2}\right)$, Higuchi kinetics model can navigate the system better, although the $R^{2}$ of the zero order kinetics model is sufficiently high to articulate that both mechanisms participated in the release of dex. The zero order model indicated that the main release mechanism was polymer erosion. However, when the drug was primarily released by diffusion, the Higuchi model provided a better fit with the data.

\section{Discussion}

A PLGA-PEG-PLGA hydrogel was prepared by a microwave assisted method. As we previously reported, the synthesis of copolymers by microwave irradiation resulted in almost pure and high quality copolymers in excellent yield [9]. The rate of the reaction increases noticeably, which lessens the preparation time from hours to minutes [42]. The conventional synthesis procedure for PLGA-PEG-PLGA takes a long time (about 15 hours), whereas the product is generated in about 5 min using the microwave assisted method.

The ${ }^{1}$ HNMR spectra indicated good accordance with previously reported PLGA-PEG-PLGA spectra, confirming the structure of the obtained copolymers [27]. The obtained copolymers demonstrated the Mn and the LA : GA ratios that were expected according to the amounts of initial materials added to the reaction.

The Mn of the copolymer increased as the LA: GA ratio was raised, since the $\mathrm{Mn}$ of each lactide monomer $(72 \mathrm{~g} / \mathrm{mol})$ is higher than that of each glycolide $(58 \mathrm{~g} / \mathrm{mol})$. The other parameter that is dependent on the LA : GA ratio is the phase transition temperature. The phase transition occurs due to the

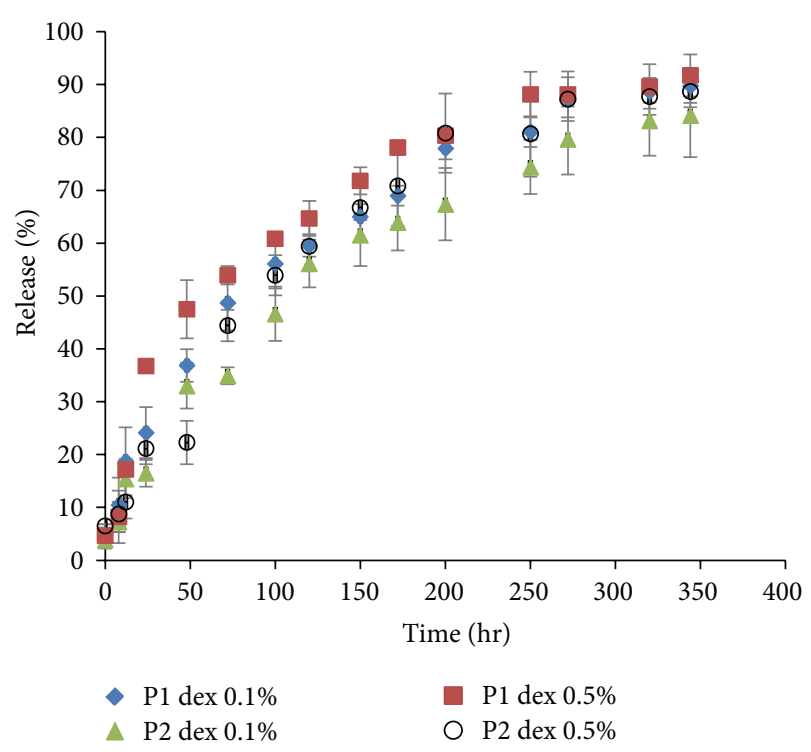

FIGURE 2: Release profile of dexamethasone (dex) from PLGA-PEGPLGA hydrogels (mean \pm SD).

specific amphiphilic structure of the PLGA-PEG-PLGA triblock copolymer, which is composed of hydrophobic PLGA and hydrophilic PEG blocks. Although PLGA is constructed of hydrophilic glycolide and hydrophobic lactide blocks, the amounts of lactide in the synthesised copolymers was 3 and 5 times greater than that of glycolide. As a result, PLGA possessed an overall hydrophobicity.

According to the iceberg theory, when hydrophobic molecules are surrounded by water, this causes a reduction in entropy and the hydrophobic sections aggregate to decrease their exposure to the aqueous phase. Before increasing the temperature and depending on the copolymer concentration and structure, the formulations were in the sol condition, which contained monomers, micelles, and group micelles dispersed in water. As the temperature increased, the hydrogen bonds within PEG and water molecules became weaker. This phenomenon also allows the arrangement of hydrophobic bridges between PLGA segments and finally the material assumes the gel structure. Further elevation of temperature causes phase separation and copolymer precipitation, which also depends on concentration and copolymer structure in a similar way to the sol-gel transition temperature $[26,43]$.

A LA : GA ratio of 5 led to occurrence of gel formation at a lower temperature due to the prevalence of hydrophobic LA, which causes a higher number of physical crosslinks by hydrophobic interactions. The gel forming temperature also depends on the copolymer concentration. The formulations with higher copolymer concentration could assume the gel shape at lower temperatures due to the higher number of copolymer chain collisions and physical interactions.

Loading of dex reduced the gel forming temperature. Our previous research that examined loading of vitamin $\mathrm{B}_{12}$ and naltrexone hydrochloride showed the same effect, especially with higher concentrations of the drug. We assumed that hydrophilic or soluble salts of drug molecules, by absorbing 
water molecules themselves, could reduce the water activity and access of PEG segments to the water molecules, thereby accelerating the phase transition at a lower temperature [26, 43].

Evaluating the release profiles indicates that, unlike what was anticipated, neither the copolymer structure nor the drug concentration had any significant influence on the rate of drug release. Since Higuchi model provided a better fit with the obtained data, diffusion appears to be the main mechanism of dex release. The amounts of release approached $100 \%$ of the loaded drug before the complete degradation of the hydrogel, so most of drug was released by diffusion. This was not unexpected for dex, given its low $\mathrm{Mw}$ and its small size. During diffusion, an increase in the drug concentration led to a higher rate of release [44]; nevertheless, it could also have led to a higher viscosity of the hydrogel (data not shown), as was explained for phase transition. The chance of LA-LA interactions increased due to the salting out mechanism. The water activity also reduces the rate of bulk degradation of the hydrogel, which would affect the rate of solute diffusion by increasing the porosity [44]. The occurrence of these phenomena resulted in an imperceptible increase in the release rate by increases in dex concentration.

Higher LA : GA ratio means more physical crosslinking, more tortuosity, and lower porosity. The size of the hydrogel pores appeared to be sufficiently small for dex to pass through without restraint even at LA : GA 5, and a negligible difference was observed in the rate of drug release between formulations with the same concentration but various copolymer structures. Qiao et al. reported the same findings and indicated that LA : GA ratio has a minor effect on drug release during the diffusion stage. They proposed that the effects of LA : GA depend on the release mechanism and that noticeable effects are seen when the drug is released by hydrogel erosion [22]. Possibly, the comparison between LA: GA 3 and a hydrogel with a much larger ratio (greater than 5) led to this noticeable difference.

\section{Conclusion}

The microwave assisted method is an appropriate technique for the synthesis of PLGA-PEG-PLGA with a high yield of reaction and an acceptable purity. The copolymer structure modulates the phase transition temperature, which is an important factor for developing in situ forming drug delivery systems. However, the structure does not appear to have a substantial effect on the release profile of dex, which is a small molecule, at least for the comparison between LA: GA 3 and 5 carried out in this study.

Loading of a drug can change the physical properties of the system. Drug concentration has a minor effect on dex release rate, although release occurs primarily via diffusion.

\section{Conflict of Interests}

The authors declare that there is no conflict of interests regarding the publication of this paper.

\section{Acknowledgment}

This work was Pharm. D. thesis of Fatemeh Kheirandish and it was financially supported by grants from Mashhad University of Medical Sciences.

\section{References}

[1] Y. Zhang, H. F. Chan, and K. W. Leong, "Advanced materials and processing for drug delivery: the past and the future," Advanced Drug Delivery Reviews, vol. 65, no. 1, pp. 104-120, 2013.

[2] K. Bowey and R. J. Neufeld, "Systemic and mucosal delivery of drugs within polymeric microparticles produced by spray drying," BioDrugs, vol. 24, no. 6, pp. 359-377, 2010.

[3] W. Jiang, R. K. Gupta, M. C. Deshpande, and S. P. Schwendeman, "Biodegradable poly(lactic-co-glycolic acid) microparticles for injectable delivery of vaccine antigens," Advanced Drug Delivery Reviews, vol. 57, no. 3, pp. 391-410, 2005.

[4] C.-M. J. Hu and L. Zhang, "Nanoparticle-based combination therapy toward overcoming drug resistance in cancer," Biochemical Pharmacology, vol. 83, no. 8, pp. 1104-1111, 2012.

[5] D. F. Emerich and C. G. Thanos, "The pinpoint promise of nanoparticle-based drug delivery and molecular diagnosis," Biomolecular Engineering, vol. 23, no. 4, pp. 171-184, 2006.

[6] Y. Qiu and K. Park, "Environment-sensitive hydrogels for drug delivery," Advanced Drug Delivery Reviews, vol. 53, no. 3, pp. 321-339, 2001.

[7] T. R. Hoare and D. S. Kohane, "Hydrogels in drug delivery: progress and challenges," Polymer, vol. 49, no. 8, pp. 1993-2007, 2008.

[8] J. H. An, H. S. Kim, D. J. Chung, D. S. Lee, and S. Kim, “Thermal behaviour of poly( $\varepsilon$-caprolactone)-poly(ethylene glycol)poly( $\varepsilon$-caprolactone) tri-block copolymers," Journal of Materials Science, vol. 36, no. 3, pp. 715-722, 2001.

[9] E. Khodaverdi, A. Golmohammadian, S. A. Mohajeri, G. Zohuri, F. S. Mirzazadeh Tekie, and F. Hadizadeh, "Biodegradable in situ gel-forming controlled drug delivery system based on thermosensitive poly( $\varepsilon$-caprolactone)-poly(ethylene glycol)-poly( $\varepsilon$-caprolactone) hydrogel," ISRN Pharmaceutics, vol. 2012, Article ID 976879, 7 pages, 2012.

[10] S. A. Hagan, A. G. A. Coombes, M. C. Garnett et al., "Polylactide-poly(ethylene glycol) copolymers as drug delivery systems. 1. Characterization of water dispersible micelleforming systems," Langmuir, vol. 12, no. 9, pp. 2153-2161, 1996.

[11] L. Chen, Z. Xie, J. Hu, X. Chen, and X. Jing, "Enantiomeric PLAPEG block copolymers and their stereocomplex micelles used as rifampin delivery," Journal of Nanoparticle Research, vol. 9, no. 5, pp. 777-785, 2007.

[12] I. Goldmints, J. F. Holzwarth, K. A. Smith, and T. A. Hatton, "Micellar dynamics in aqueous solutions of PEO-PPO-PEO block copolymers," Langmuir, vol. 13, no. 23, pp. 6130-6133, 1997.

[13] B. Jeong, Y. H. Bae, and S. W. Kim, "Biodegradable thermosensitive micelles of PEG-PLGA-PEG triblock copolymers," Colloids and Surfaces B, vol. 16, no. 1-4, pp. 185-193, 1999.

[14] F. Ahmed and D. E. Discher, "Self-porating polymersomes of PEG-PLA and PEG-PCL: hydrolysis-triggered controlled release vesicles," Journal of Controlled Release, vol. 96, no. 1, pp. 37-53, 2004.

[15] S. Y. Park, D. K. Han, and S. C. Kim, "Synthesis and characterization of star-shaped PLLA-PEO block copolymers with temperature-sensitive sol-gel transition behavior," Macromolecules, vol. 34, no. 26, pp. 8821-8824, 2001. 
[16] N. Kumar, M. N. V. Ravikumar, and A. J. Domb, "Biodegradable block copolymers," Advanced Drug Delivery Reviews, vol. 53, no. 1, pp. 23-44, 2001.

[17] A. K. Bajpai, S. K. Shukla, S. Bhanu, and S. Kankane, "Responsive polymers in controlled drug delivery," Progress in Polymer Science, vol. 33, no. 11, pp. 1088-1118, 2008.

[18] A. Hatefi and B. Amsden, "Biodegradable injectable in situ forming drug delivery systems," Journal of Controlled Release, vol. 80, no. 1-3, pp. 9-28, 2002.

[19] C. B. Packhaeuser, J. Schnieders, C. G. Oster, and T. Kissel, "In situ forming parenteral drug delivery systems: an overview," European Journal of Pharmaceutics and Biopharmaceutics, vol. 58, no. 2, pp. 445-455, 2004.

[20] K. S. Anseth, A. T. Metters, S. J. Bryant, P. J. Martens, J. H. Elisseeff, and C. N. Bowman, "In situ forming degradable networks and their application in tissue engineering and drug delivery," Journal of Controlled Release, vol. 78, no. 1-3, pp. 199209, 2002.

[21] G. M. Zentner, R. Rathi, C. Shih et al., "Biodegradable block copolymers for delivery of proteins and water-insoluble drugs," Journal of Controlled Release, vol. 72, no. 1-3, pp. 203-215, 2001.

[22] M. Qiao, D. Chen, X. Ma, and Y. Liu, "Injectable biodegradable temperature-responsive PLGA-PEG-PLGA copolymers: synthesis and effect of copolymer composition on the drug release from the copolymer-based hydrogels," International Journal of Pharmaceutics, vol. 294, no. 1-2, pp. 103-112, 2005.

[23] S. Chen and J. Singh, "Controlled release of growth hormone from thermosensitive triblock copolymer systems: in vitro and in vivo evaluation," International Journal of Pharmaceutics, vol. 352, no. 1-2, pp. 58-65, 2008.

[24] M. Qiao, D. Chen, X. Ma, and H. Hu, "Sustained release of bee venom peptide from biodegradable thermosensitive PLGAPEG-PLGA triblock copolymer-based hydrogels in vitro," Die Pharmazie, vol. 61, no. 3, pp. 199-202, 2006.

[25] Y. J. Kim, S. Choi, J. J. Koh, M. Lee, K. S. Ko, and S. W. Kim, "Controlled release of insulin from injectable biodegradable triblock copolymer," Pharmaceutical Research, vol. 18, no. 4, pp. 548-550, 2001.

[26] E. Khodaverdi, F. S. M. Tekie, S. A. Mohajeri, F. Ganji, G. Zohuri, and F. Hadizadeh, "Preparation and investigation of sustained drug delivery systems using an injectable, thermosensitive, in situ forming hydrogel composed of PLGA-PEG-PLGA," AAPS PharmSciTech, vol. 13, no. 2, pp. 590-600, 2012.

[27] S. Chen, R. Pieper, D. C. Webster, and J. Singh, “Triblock copolymers: synthesis, characterization, and delivery of a model protein," International Journal of Pharmaceutics, vol. 288, no. 2, pp. 207-218, 2005.

[28] L. Yu, Z. Zhang, and J. Ding, "Influence of la and GA sequence in the PLGA block on the properties of thermogelling PLGAPEG-PLGA block copolymers," Biomacromolecules, vol. 12, no. 4, pp. 1290-1297, 2011.

[29] E. Khodaverdi, F. Hadizadeh, F. S. M. Tekie, A. Jalali, S. A. Mohajeri, and F. Ganji, "Preparation and analysis of a sustained drug delivery system by PLGA-PEG-PLGA triblock copolymers," Polymer Bulletin, vol. 69, no. 4, pp. 429-438, 2012.

[30] M. N. Silverman and E. M. Sternberg, "Glucocorticoid regulation of inflammation and its functional correlates: from HPA axis to glucocorticoid receptor dysfunction," Annals of the New York Academy of Sciences, vol. 1261, no. 1, pp. 55-63, 2012.

[31] N. Rohleder, J. M. Wolf, and O. T. Wolf, "Glucocorticoid sensitivity of cognitive and inflammatory processes in depression and posttraumatic stress disorder," Neuroscience and Biobehavioral Reviews, vol. 35, no. 1, pp. 104-114, 2010.

[32] M. Markman, V. Sheidler, and D. S. Ettinger, "Antiemetic efficacy of dexamethasone. Randomized, double-blind, crossover study with prochlorperazine in patients receiving cancer chemotherapy," The New England Journal of Medicine, vol. 311, no. 9, pp. 549-552, 1984.

[33] S. M. Grunberg, "Antiemetic activity of corticosteroids in patients receiving cancer chemotherapy: dosing, efficacy, and tolerability analysis," Annals of Oncology, vol. 18, no. 2, pp. 233240, 2007.

[34] R. E. Coleman, "Glucocorticoids in cancer therapy," Biotherapy, vol. 4, no. 1, pp. 37-44, 1992.

[35] I. Herr, E. Ucur, K. Herzer et al., "Glucocorticoid cotreatment induces apoptosis resistance toward cancer therapy in carcinomas," Cancer Research, vol. 63, no. 12, pp. 3112-3120, 2003.

[36] D. L. Deifenderfer, A. M. Osyczka, G. C. Reilly, and P. S. Leboy, "BMP responsiveness in human mesenchymal stem cells," Connective Tissue Research, vol. 44, no. 1, pp. 305-311, 2003.

[37] Y. Ogata, M. Yamauchi, R. H. Kim, J. J. Li, L. P. Freedman, and J. Sodek, "Glucocorticoid regulation of bone sialoprotein (BSP) gene expression-identification of a glucocorticoid response element in the bone sialoprotein gene promoter," European Journal of Biochemistry, vol. 230, no. 1, pp. 183-192, 1995.

[38] A. Martins, A. R. C. Duarte, S. Faria, A. P. Marques, R. L. Reis, and N. M. Neves, "Osteogenic induction of hBMSCs by electrospun scaffolds with dexamethasone release functionality," Biomaterials, vol. 31, no. 22, pp. 5875-5885, 2010.

[39] S. Srisawasdi and P. Pavasant, "Different roles of dexamethasone on transforming growth factor- $\beta 1$-induced fibronectin and nerve growth factor expression in dental pulp cells," Journal of Endodontics, vol. 33, no. 9, pp. 1057-1060, 2007.

[40] B. Alliot-Licht, G. Bluteau, D. Magne et al., "Dexamethasone stimulates differentiation of odontoblast-like cells in human dental pulp cultures," Cell and Tissue Research, vol. 321, no. 3, pp. 391-400, 2005.

[41] Y. N. Kalia and R. H. Guy, "Modeling transdermal drug release," Advanced Drug Delivery Reviews, vol. 48, no. 2-3, pp. 159-172, 2001.

[42] A. Sosnik, G. Gotelli, and G. A. Abraham, "Microwave-assisted polymer synthesis (MAPS) as a tool in biomaterials science: how new and how powerful," Progress in Polymer Science, vol. 36, no. 8, pp. 1050-1078, 2011.

[43] A. A. Ghahremankhani, F. Dorkoosh, and R. Dinarvand, "PLGA-PEG-PLGA tri-block copolymers as in situ gel-forming peptide delivery system: effect of formulation properties on peptide release," Pharmaceutical Development and Technology, vol. 13, no. 1, pp. 49-55, 2008.

[44] B. Amsden, "Solute diffusion within hydrogels. Mechanisms and models," Macromolecules, vol. 31, no. 23, pp. 8382-8395, 1998. 

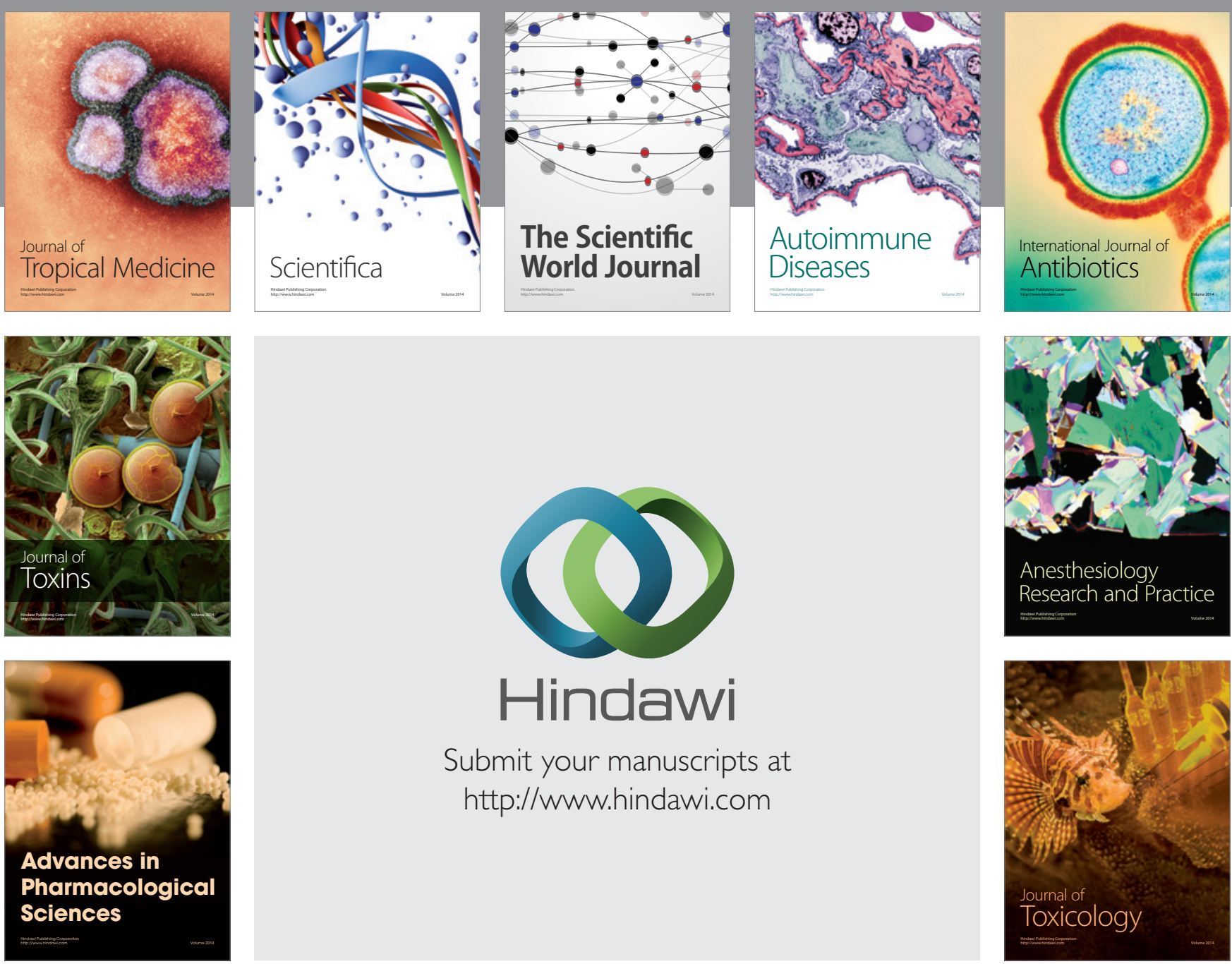

\section{Hindawi}

Submit your manuscripts at

http://www.hindawi.com
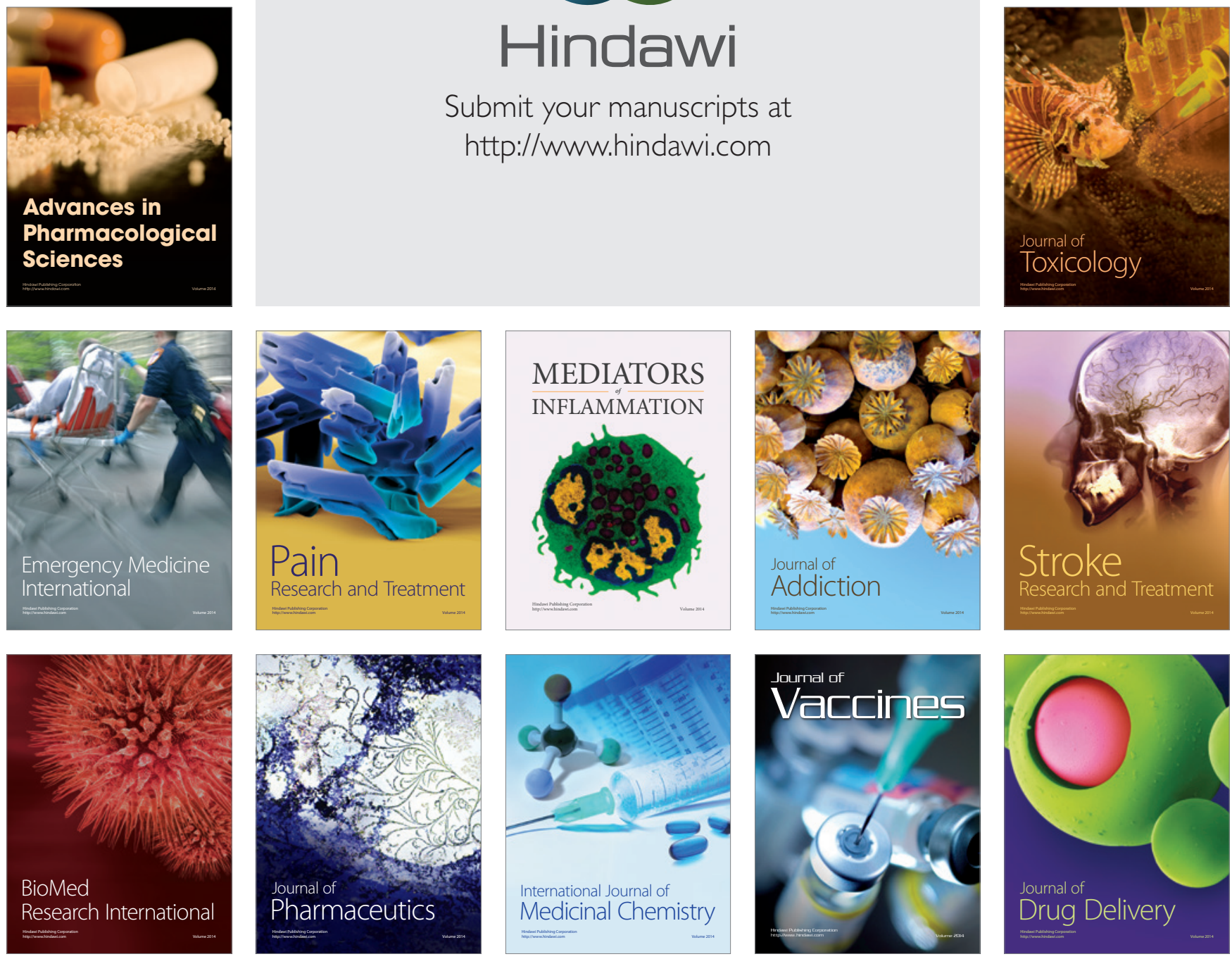